colonization of dry land, a soil-plant-animal-soil cycle arose, from which phosphorus was removed in small quantities in the formation of bone beds, fossil fish or guano deposits. With the development of agriculture in historic times, however, the phosphorus cycle has been seriously upset, for systematic cropping reduces the reserves in the soil more quickly than they can be renewed from fresh sources. In the past fow centuries man has attempted to restore the phosphorus balance by the use of fertilizers, derived largely from natural deposits; but he has also accelerated the transference of phosphorus from plant and animal life to the sea, thus speeding up its cyclical migration in a two-fold manner. Although this has been of undoubted benefit to man, it will ultimately lead to a state of bankruptcy with regard to the element. The world reserves of workable mineral phosphate are within measurable distance of exhaustion, and although new sources may be discovered, a planned economy in their utilization seems called for, as no substitute for phosphate exists and it is essential to the survival of a large human population. The address, which includes a historical account of phosphatic fertilizers, is to be published in the January issue of the South Eastern Naturalist and Antiquary.

\section{Mathematics in China}

IN addition to work directly for the war effort and in spite of difficulties of communication, mathematicians in China are able to produce a considerable amount of new work of the highest quality. In particular, we may mention Prof. L. K. Hua, of the Tsing Hua University in Kunming, whose visit to Cambridge during 1936-38 will be remembered. The following information has been received through the British Council Cultural Scientific Office at Chungking. Prof. Hua has just completed a booklet on additive prime number theory which will be published by the Academy of Sciences of the U.S.S.R. The first of a series of papers on the theory of automorphic functions of a matrix variable has just been published in the American Journal of Mathematics. Related to this is a theory of modular functions connected with linear associative algebras, which is so far unpublished. Another field in which Prof. Hua has been working is that of the geometry of matrices, related to topological algebra. In addition, Prof. Hua has continued his studies in the geometry of numbers and, in extending theories due to Minkowski and Dr. K. Mahler, has discovered a new type of convex body.

\section{Astronomical Observations in Spain}

IN the issue for 1944 of the Boletin Astronómico Del Observatorio De Madrid, E. Gullón supplies a résumé of the observations of solar prominences dur. ing September-December 1939. Owing to the removal of certain equipment from Valencia to Madrid and to other causes, observations could not commence before September 1. Sunspot observations during the same period were made by E. Gullon and Martín Lorón with the $20-\mathrm{cm}$. Grubb equatorial, and the results are shown on pages 14-16. Solar prominences during 1940 were observed by E. Gullón and the results are given in the same form as those observed during 1939. The last section of the bulletin deals with sunspot observations carried out by $\mathrm{E}$. Gullón and Martín Lorón at Madrid and Valencia in 1940. Those at Madrid were made by means of a Herschel helioscope mounted on the $20-\mathrm{cm}$.
Grubb equatorial, focal length $3 \mathrm{~m}$., and those at Valencia were made with another equipment of a similar type on the $15-\mathrm{cm}$. Grubb, and with a focal length $2.20 \mathrm{~m}$.

\section{Swedish-made Drugs}

According to the August issue of the AngloSwedish Review, a new local anæsthetic has been discovered which in several respects far surpasses novocaine, which Sweden had hitherto to import. This new anæsthetic has been named $L L 30$, the letters standing for the names of two young scientific workers Lövgren and Lundquist, and the figure representing the number of anæsthetic com. pounds tried and discarded during their six years of investigation. $L L 30$ is now being made on a commercial scale by the Astra concern of Södertälje not far from Stockholm, where penicillin is also being manufactured. Sulphonamide preparations are being manufactured from Swedish raw materials, and its price is now down to half that of the imported foreign preparations.

\section{Books on Historical Medicine and Science}

THE annotated catalogue issued by Schuman's, 30 East 70th Street, New York, under the name of "Medical Miscellany List ' $\mathrm{J}$ '", includes, besides a large number of miscellaneous works on medicine and science, two sections devoted respectively to neurology and psychiatry and war medicine. The miscellaneous works include books by Baillou on epidemiology, diseases of the skin by Alibert, anthropology by Blumenbach, physiological opties by Helmholtz, as well as the first fifteen volumes of the Memoirs of the Royal Academy of Surgery of Paris. Among the books on neurology and psychiatry are works by BrownSéquard, Freud, Janet, Kraft-Ebing, Puschmann, Spallazani and Vesalius. The section on war medicine contains Hans von Gerssdorff's field book of surgery (1528), John Pringle's "Observations on the Diseases of the Army" (1765) van Swieten's 'Diseases incident to Armies" (1776) and works on the American Civil War (1861-1870), including documents concerning the United States Sanitary Commission.

\section{Announcements}

After nearly two years in China, Dr. Joseph Needham, director of the British Council Cultural Scientific Office in China, has returned to Great Britain for consultations. He will be returning to China early in the New Year.

Prof. J. M. Mackintosh, professor of public health in the University of London, has been appointed dean of the London School of Hygiene and Tropical Medicine as from January 1, 1945.

AT the annual general meeting of the Scientific Instrument Manufacturers Association of Great Britain, Ltd., the following officers were elected: President, Mr. F. Wakeham; Vice-Presidents, Mr. J. Hasselkus and Mr. J. T. Offer; Hon. Treasurer, Mr. J. E. C. Bailey; Hon. Secretary, Mr. G. A. Whipple.

The Association of Scientific Workers is organizing a conference to discuss the use of science in the post-war world, to be held at the Caxton Hall, London, S.W.1, during February 17-18, 1945. Further particulars will be obtainable in due course from the Association of Scientific Workers, Hanover House, 73 High Holborn, London, W.C.1. 